\title{
Two-step hydrolysis of Japanese cedar as treated by semi-flow hot- compressed water
}

\section{AUTHOR(S):}

Phaiboonsilpa, Natthanon; Yamauchi, Kazuchika; Lu, Xin; Saka, Shiro

\section{CITATION:}

Phaiboonsilpa, Natthanon ... [et al]. Two-step hydrolysis of Japanese cedar as treated by semi-flow hot-compressed water. Journal of Wood Science 2010, 56(4): 331-338

\section{ISSUE DATE:}

2010-08

URL:

http://hdl.handle.net/2433/128911

\section{RIGHT:}

The original publication is available at www.springerlink.com; この論文 は出版社版でありません。引用の際には出版社版をご確認ご利用くだ さい。; This is not the published version. Please cite only the published version. 


\section{Two-step hydrolysis of Japanese cedar as treated by semi-flow}

\section{hot-compressed water}

${ }^{1}$ Graduate School of Energy Science, Kyoto University, Japan

${ }^{2}$ On the leave from College of Food Science and Technology, Nanjing Agricultural University, Nanjing, 210095 China, presently College of Food Science and Engineering, Northwest A\&F University, Yangling, Shaanxi, 712100 China

*Corresponding author

Address: Department of Socio-Environmental Energy Science, Graduate School of Energy Science, Kyoto University, Yoshida-honmachi, Sakyo-ku, Kyoto, 606-8501, Japan Tel/Fax: +81-75-753-4738 E-mail: saka@energy.kyoto-u.ac.jp

Key words Japanese cedar, hot-compressed water, hemicellulose, cellulose, lignin

Footnote: This work was presented in part at the 55th Annual Meeting of the Japan Wood Research Society, Matsumoto, Japan, March 2009, the World Renewable Energy Congress 2009 - Asia, Bangkok, Thailand, May 2009 and the 18th Annual Meeting of Japanese Institute of Energy, Sapporo, Japan, July 2009. 


\section{Abstract} $12.24 \%$ could not be hydrolyzed and remained as the water-insoluble residue composed Japanese cedar, their decomposition pathways were independently proposed.

Two-step hydrolysis of Japanese cedar (Cryptomeria japonica) was studied as treated by semi-flow hot-compressed water at $230^{\circ} \mathrm{C} / 10 \mathrm{MPa}$ for $15 \mathrm{~min}$ and $280^{\circ} \mathrm{C} / 10 \mathrm{MPa}$ for 30 min as the first and second stages, respectively. As a result, at the first stage, hemicelluloses and para-crystalline cellulose whose crystalline structure is somewhat disordered were found to be selectively hydrolyzed as well as lignin decomposition, while crystalline cellulose at the second stage. Totally $87.76 \%$ of Japanese cedar could be liquefied by the hot-compressed water and were primarily recovered as various hydrolyzed products, dehydrated, fragmented and isomerized compounds, as well as, organic acids in the water-soluble portion. The rest of entirely of lignin. Based on the distributions of various products from hemicelluloses in 


\section{Introduction}

In an attempt to alleviate both of the environmental and energy security problems, ethanol produced from various biomass has long been proposed as a promising biofuel for several decades ${ }^{1}$. Lignocellulosics can be utilized to obtain fermentable saccharides for the bioethanol production. However, unlike sugar and starch, the development of bioethanol production from them has been impeded by their great resistance to hydrolysis due to the cellulose crystallinity and presence of lignin. Therefore, various biological, chemical and/or physical treatments such as enzymatic saccharification, acid hydrolysis, alkali process, steam explosion, and supercritical and subcritical treatments have been developed ${ }^{2-7}$.

However, one drawback of using acid or alkali is the necessity for neutralization and separation ${ }^{2}$. In addition, Aida et al. ${ }^{8}$ elucidated that an increase in water temperature $\left(350-400^{\circ} \mathrm{C}\right)$ and pressure (40-70MPa) did not only heighten the dehydration of glucose to 5-hydroxymethylfurfural (5-HMF), but also enhanced the formation of 1,2,4-benzenetriol (BTO), resulting in a greater loss of saccharides and inhibition effect in the subsequent fermentability. Although the liquefaction rate became extremely high as treated cellulose by subcritical water, it was found that the hydrolysis rate of cellulose was much lower than the decomposition rate of glucose and its oligomers ${ }^{9}$. The economic and environmental constraints, moreover, limit the applicability of these known methods. Thus, hot-compressed water, milder conditions with high ionic product, seems to be a promising alternative as both 
1 environmentally friendly solvent and attractive reaction media for a variety of applications ${ }^{10-11}$.

2 Hot-compressed water refers to the water at supercritical or subcritical state, or at sufficiently

3 high pressure and temperature ${ }^{12}$.

4

5 could not be optimized at the same treatment severity ${ }^{2,6,13-14}$. Therefore, two-step treatment,

Besides, it has long been realized that the hydrolysis of cellulose and hemicelluloses with the first stage performed at low severity to hydrolyze the hemicelluloses and the second

$9 \quad$ saccharide yields ${ }^{6,13-14}$. stage in which the solid residue from the first stage is consecutively treated, but at a higher degree of severity, has gained a great amount of attention as an alternative to increase Ando et al. ${ }^{10}$ investigated the decomposition behavior of bamboo, chinquapin and Japanese cedar as treated by two-step hot-compressed water at $180^{\circ} \mathrm{C}$ for $20 \mathrm{~min}$ and $285^{\circ} \mathrm{C}$ for $7 \mathrm{~min}$ using the semi-flow-type reactor with a flow-rate of $10 \mathrm{~mL} / \mathrm{min}$ under $9.8 \mathrm{MPa}$. In this report, however, quantitative assessments of hydrolyzed saccharides and various products derived from hemicelluloses and cellulose, together with a discussion of their decomposition pathways, have not been sufficiently clarified.

In our previous work ${ }^{15}$, two-step hydrolysis of Japanese beech (Fagus crenata) as one of the hardwoods treated by semi-flow hot-compressed water has been conducted. As a result, hemicelluloses and cellulose were found to be independently hydrolyzed in the first and second stages of the treatment, respectively. In order to gain better insights into the two-step 
1 hot-compressed water treatment of various lignocellulosics, in this work, therefore, two-step

2 hydrolysis of Japanese cedar (Cryptomeria japonica) as one of the softwoods treated by

3 semi-flow hot-compressed water was investigated. Not only qualitative assessments of

4 various hydrolyzed products, dehydrated, fragmented and isomerized compounds as well as

5 organic acids recovered in the water-soluble portion, but also the quantification of these

6 products were reported. Based on this line of informative evaluations, the independent

7 decomposition pathways of hemicelluloses and cellulose were eventually proposed.

8

9

\section{Materials and methods}

\section{Material and chemicals}

Extractive-free wood flour of Japanese cedar (Cryptomeria japonica) was prepared ${ }^{15,16}$. The weight percentages of products were calculated on the oven-dried extractive-free wood flour basis. Table 1 shows the chemical compositions of the extractive-free Japanese cedar, determined by Klason lignin determination $\operatorname{method}^{17}$ for lignin and the obtained acid hydrolysate for hemicelluloses and cellulose. All chemicals used in this study were of reagent grade without purification.

\section{Hot-compressed water treatment and fractionation of the treated samples}

The semi-flow hot-compressed water biomass conversion system and operational 
1 procedures as described previously ${ }^{15}$ were used in this study. Based on our preliminary

2 experiments ${ }^{16}$ to explore the relationship between treatment temperature under pressurized

3 conditions (10MPa) and the degree of hydrolysis of hemicelluloses and cellulose, the

4 treatment temperatures applied for the two-step treatment were set at 230 and $280^{\circ} \mathrm{C}, 10 \mathrm{MPa}$

5 at the flow-rate of $10.0 \mathrm{~mL} / \mathrm{min}$. The hot-compressed water-soluble portion was collected

6 every $1 \mathrm{~min}$ by the fraction collector. After settling in the ambient temperature and pressure

7 for 12 hours, water-soluble portion was obtained by filtration with the $0.45-\mu \mathrm{m}$ membrane

8 prior to subsequent analyses. On the other hand, water-insoluble residue left over the reaction

9 cell after the treatment was collected, oven-dried and studied on its chemical compositions.

\section{Analytical methods}

The analyses of the water-soluble portion were made by the high-performance anion-exchange chromatography (HPAEC), high-performance liquid chromatography (HPLC), gas chromatography-mass spectrometry (GC-MS) and capillary electrophoresis (CE). The same analysis systems and operating conditions were applied in accordance with our previous paper $^{15}$.

Post-hydrolysis by dilute sulfuric acid was performed to estimate all recovered oligosaccharides in the water-soluble portion in terms of acid-hydrolyzed monosaccharides ${ }^{18}$. The obtained acid hydrolysate was neutralized with barium hydroxide, $\mathrm{Ba}(\mathrm{OH})_{2}$, and then 
1 filtrated by $0.45-\mu \mathrm{m}$ membrane filter before HPLC analysis using the HPX-87P column.

2 Distilled water was used as an eluent, and the system operated at the flow-rate and

3 temperature of $0.6 \mathrm{~mL} / \mathrm{min}$ and $85^{\circ} \mathrm{C}$, respectively. The amount of the oligosaccharides was

4 then calculated based on Eq. 1 as follows:

5
Oligosaccharides $(\mathrm{wt} \%)=$ Total monosaccharide in acid hydrolysate $(\mathrm{wt} \%)-$

Monosaccharide in water-soluble portion (wt\%)

(Eq. 1)

\section{Quantification of products in water-soluble portion}

All the product percentages on the oven-dried weight of original wood flour were calculated by using the peak area ${ }^{15}$ of chromatograms obtained from the HPAEC, HPLC, CE and GC-MS, as shown in Figs. 1-6. All the plots of product percentages shown in the figures were not exactly based on the real scale. Some of them were shifted by additional surpluses to make a clear perception of each production trend.

\section{Results and discussion}

\section{Hydrolysis of major cell wall components by hot-compressed water}

As treated by the two-step hot-compressed water $\left(230^{\circ} \mathrm{C} / 10 \mathrm{MPa} / 15 \mathrm{~min}\right.$ and $\left.280^{\circ} \mathrm{C} / 10 \mathrm{MPa} / 30 \mathrm{~min}\right), 87.76 \%$ of extractive-free Japanese cedar wood flour was liquefied 
1 and primarily recovered as various compounds in the water-soluble portion, while the rest of

$2 \quad 12.24 \%$ was not hydrolyzed and remained as the water-insoluble residue composed entirely of

3 lignin, which was confirmed by Klason lignin determination. For the obtained water-soluble

4 portion, the produced compounds were studied.

As seen in the temperature profile in Fig. 1, two-step treatment was performed over the wood flour of Japanese cedar. The dash lines indicate the transient time during an increase in temperature, while the solid lines depict the first and second stages of treatment at $230^{\circ} \mathrm{C}$ for $15 \mathrm{~min}$ and $280^{\circ} \mathrm{C}$ for $30 \mathrm{~min}$, respectively, as shown in the real temperature profile. The hydrolyzed products obtained from hemicelluloses and cellulose are shown. mannose, glucose and oligomeric glucomannan, galactose and acetic acid were produced. Besides, xylo-saccharides which include xylose and xylo-oligosaccharides, such as xylobiose, xylotriose, xylotetraose, xylopentaose, xylohexaose and the molecules with higher degree of polymerization (DP), arabinose and glucuronic acid were also recovered at this stage. In case of the production of acetic acid and glucuronic acid, since the amounts are relatively small compared to the others in Fig. 1, more apparent production trends of them can be seen later in Fig. 8. Therefore, these hydrolyzed products must originate from the major and minor hemicelluloses of the softwood, arabino-4-O-methylglucuronoxylan ${ }^{14,19-20}$, respectively. 
in the molar ratio of galactose:glucose:mannose with an acetyl residue per 48 monosaccharide in the molar ratio of arabinose:xylose with a glucuronic acid residue per 118 monosaccharide units of the xylan backbone. These results are in agreement with those in the literature to some extent, however, the numbers of acetyl and acid residues are relatively smaller than the ones reported previously ${ }^{19}$. This might be due perhaps to the fact that they were not fully recovered in those forms.

Fig. 2 depicts various monosaccharides produced from Japanese cedar. In the first stage, mannose, galactose, xylose and arabinose were found. However, it is obvious that the amounts of mannose and xylose are much lesser than those of glucomanno-saccharides and xylo-saccharides (Fig. 1), indicating that most of those hydrolyzed saccharides were recovered as in the oligomeric forms. shown by an arrow but also at the second stage shown by the inserted figure. Since hemicelluloses are supposed to be hydrolyzed in the first stage, the observed small peak of mannose and fructose at the second stage must be from cellulose. In addition, mannose and fructose are known as isomerized products of glucose in subcritical and supercritical water treatments ${ }^{21-22}$. This isomerization to mannose and fructose was ensured by the treatment of 
1 D-glucose under the same hot-compressed water conditions. Such an isomerization of glucose

2 was also observed in our previous work on Japanese beech ${ }^{15}$.

On cello-saccharides which include glucose and cello-oligosaccharides, such as

4 cellobiose, cellotriose, cellotetraose, cellopentaose, cellohexaose and higher DP molecules, as

5 shown in Fig. 1, they were produced from 10 to $55 \mathrm{~min}$ in retention time. However, the one in

6 the first stage (10-25 $\mathrm{min}$ ) would not be from crystalline cellulose because in the preliminary

7 experiment the crystalline structure of cellulose remained unchanged in such a temperature

8 around $230^{\circ} \mathrm{C}^{16}$. Therefore, the cello-saccharides just between the first and second stages

9 (10-25min) could be from para-crystalline cellulose, whose crystalline structure is somewhat disordered $^{23}$.

In contrast to hardwoods, the dominating hemicellulose in softwoods is glucomannan which can produce a significant amount of glucose as the hydrolyzed product. However, there was a production of glucose and its oligomers also from the hydrolysis of para-crystalline cellulose, leading to indistinguishable sources of them in the first stage. Since most of the hydrolyzed saccharides from glucomannan were recovered in the form of oligomeric glucomannan as described before, the glucose from glucomannan is assumed to be negligible. Moreover, upon the assumption that a single glucose residue links to the mannose residue evenly in the native glucomannan backbone, therefore, the oligomeric glucomannan can be differentiated from the cello-oligosaccharides such as cellobiose, cellotriose, cellotetraose, 
1 cellopentaose and cellohexaose. Thus, those cello-oligosaccharides (DP1 5) detected by the

2 HPAEC analysis, can be assumed to be exclusively from para-crystalline cellulose.

3 Consequently, the amount of glucose derived from oligomeric glucomannan could then be

4 estimated by the following equation.

Glucose from oligomeric glucomanan $(\mathrm{wt} \%)=$

Total glucose in acid hydrolysate (wt\%) - Cello-oligosaccharides

(DP1 5) in water-soluble portion (wt\%)

The hemicelluloses were assumed to be completely hydrolyzed in the first stage. On the other hand, cello-saccharides produced in the second stage were only from cellulose and thus determined ordinarily. By this line of calculations, the glucomanno-saccharides and cello-saccharides could be computed and plotted as shown in Fig. 1.

From the results as in Figs. 1 and 2, this two-step process has been proved to be efficient to separately hydrolyze hemicelluloses and crystalline cellulose. Although there was the hydrolysis of para-crystalline cellulose overlapping with the hemicelluloses in the first stage, a relative trace amount in its production compared with that from the hemicelluloses could be neglected. Therefore, these two important chemical components can be successfully chased independently by this process. 
Upon lignin, it was found that its monomeric products were firstly recovered before the

temperature reached $230^{\circ} \mathrm{C}$ as shown in Fig. 3. This finding accords with the literature reporting that lignin degradation was probably achieved at the temperature below $200^{\circ} \mathrm{C}^{14}$. Among these compounds, coniferyl alcohol, coniferyl aldehyde, isoeugenol and vanillin were primarily found in the first stage as hydrolyzed monomeric lignin-derived products. It was certainly proved that all of them were derived from guaiacyl unit of softwood lignin. Apart from these monomeric lignin-derived products, the amounts of its dimeric, trimeric and higher products were estimated by subtracting the monomeric products from the whole soluble lignin, as described in our previous paper ${ }^{15}$. More detail in lignin study will be published elsewhere.

\section{Decomposition of hydrolyzed products from hemicelluloses and cellulose}

After the hydrolysis of hemicelluloses and cellulose discussed above, the hydrolyzed products are further decomposed if the treatment is prolonged by hot-compressed water. Generally, they are further decomposed by dehydration and fragmentation reactions ${ }^{24}$. Since the decomposed products would lead to an inhibitory effect on later fermentation process for ethanol production ${ }^{25}$, it is important to know its decomposition pathway.

Fig. 4 shows the obtained dehydrated products of 5-HMF, furfural and levoglucosan.

Generally, 5-HMF is considered as a dehydrated product from hexoses such as glucose,

mannose and galactose, while furfural from pentoses such as xylose and arabinose ${ }^{14,21,26}$. 
1 Levoglucosan, particularly, is a dehydrated product from glucose ${ }^{21}$. As softwood

2 hemicelluloses are composed of both hexoses and pentoses, not only furfural but also 5-HMF

3 and levoglucosan were possibly found in the first stage. Nonetheless, fewer amounts of them

4 were obtained, compared with the ones in the second stage. This is due to more severe

5 conditions in second stage that can enhance the degree of dehydration.

7 finding has been realized in our previous work ${ }^{15}$. Therefore, this obtained result can confirm

8 that furfural is not only produced from pentoses but also from hexoses such as glucose under

9 the hot-compressed water treatment. The possible formation of furfural without pentoses is possibly via 5-carbon ketoses pathway as proposed in the literature ${ }^{27}$.

In Fig. 5, methylglyoxal and glycolaldehyde can be seen in both first and second stages,

while erythrose in the second stage only. Therefore, at the first stage, pentoses such as xylose and arabinose from xylan hemicellulose would be decomposed to glycolaldehyde and glyceraldehyde, and then glyceraldehyde was dehydrated to methylglyoxal as observed in glyceraldehyde pathway of hexose fragmentation ${ }^{28}$. However, one molecule of pentose can give one glycolaldehyde and one methylglyoxal according to the carbon balance. Therefore, the ratio among their weight percentages should be approximately $1: 1$. However, it is obvious that much more methylglyoxal was produced. Thus, there should be another source for methylglyoxal production. Undoubtedly, hexoses such as glucose, mannose and galactose, 
1 from glucomannan hemicellulose could be fragmented into methylglyoxal produced via

2 glyceraldehyde/dihydroxyacetone pathway in hexose fragmentation ${ }^{21,29}$, leading to the

3 additional amount of methylglyoxal over the glycolaldehyde.

4

5 retro-aldol condensation ${ }^{21,30}$ occurred in glycolaldehyde/erythrose pathway, while

6 methylglyoxal was produced via glyceraldehyde/dihydroxyacetone pathway in hexose

7 fragmentation as mentioned above. However, under the conditions applied, glyceraldehyde and its isomerized dihydroxyacetone in glyceraldehyde pathway were not detected in either from hydrolysis of acetyl group in the major one, $O$-acetyl-galactoglucomannan. Acetic acid stage. This would be because the dehydration reaction of glyceraldehyde is so fast consecutively to methylglyoxal and/or organic acids ${ }^{28}$.

\section{Production of organic acids}

Organic acids are considered as decomposition products of the dehydrated and fragmented compounds ${ }^{21}$. As in Fig. 6, the produced organic acids are glucuronic acid, acetic acid, lactic acid, glycolic acid and formic acid. However, glucuronic acid was the hydrolyzed product from the glucuronic acid residue in the minor softwood hemicellulose, arabino-4-O-methylglucurono-xylan, while acetic acid found in the first stage mostly came in the second stage, on the other hand, must be a result of the decomposition of cellulose 
1 and/or lignin ${ }^{15,31}$. In addition, the production of lactic acid, glycolic acid and formic acid were

2 found in both stages of the treatment, thus, indicating that the decomposition of dehydrated

3 and fragmented compounds took place. Acrylic acid and levulinic acid were not detected

4 under the conditions applied.

\section{Overall compounds produced from hemicelluloses, cellulose and lignin}

Table 2 summarizes the yields of the produced compounds from hemicelluloses, cellulose and lignin separately as treated by two-step hot-compressed water at $230^{\circ} \mathrm{C} / 10 \mathrm{MPa} / 15 \mathrm{~min}$ and $280^{\circ} \mathrm{C} / 10 \mathrm{MPa} / 30 \mathrm{~min}$. The results clearly shows that the water-soluble portion contained 40.14(40.21-0.07)\% hydrolyzed products as in forms of various saccharides, uronic acid and acetic acid $(19.49(=19.24+0.25) \%$ from hemicelluloses and $20.65(=2.95+17.77-0.07) \%$ from cellulose), and their decomposed compounds (dehydrated and fragmented compounds plus organic acids) to be $8.69(=4.06+3.88+0.68+0.07) \%$, while lignin-derived products were $20.36(=13.90+6.46) \%$. Apart from these, $18.57 \%$ unidentified products in the water-soluble portion were obtained and considered as unknowns. On the other hand, the water-insoluble residue was only $12.24 \%$ composed entirely of lignin.

The hydrolyzed saccharides from $O$-acetyl-galactoglucomannan hemicellulose included glucomanno-saccharides, such as mannose, glucose and oligomeric glucomannan, galactose 
1 and acetic acid, while those from arabino-4- $O$-methylglucuronoxylan hemicellulose were

2 xylose, xylo-oligosaccharides, arabinose and glucuronic acid. On the other hand, saccharides

3 from cellulose included glucose and cello-oligosaccharides as well as fructose, an isomerized

4 product from glucose.

Recently, Matsunaga et al. ${ }^{32}$ treated Japanese cedar with subcritical water by using the semi-flow-type reactor. It was reported that the highest total recovered saccharide yield of about $37.26 \mathrm{wt} \%$ on extractive-free wood flour basis could be achieved at $310-320^{\circ} \mathrm{C}, 25 \mathrm{MPa}$ and $65 \mathrm{~g} / \mathrm{min}$ flow-rate without any pretreatment to improve wettability of the wood meal. In comparison with the total hydrolyzed compounds obtained in this study $(40.14 \mathrm{wt} \%)$, the two-step hot-compressed water treatment have been proved to give higher yields of 11 saccharides.

Since chemical composition of Japanese cedar on an extractive-free basis is 19.10, 48.32 and $32.58 \%$, respectively, for hemicelluloses, cellulose and lignin, the total products from hemicelluloses accounted for $112.93(=(21.32+0.25) / 19.10 \times 100) \mathrm{wt} \%$, lignin $100.06(=(13.90+6.46+12.24) / 32.58 \times 100) \mathrm{wt} \%$, while cellulose $56.42(=(2.95+24.31) / 48.32$ $\times 100) w t \%$ on each constituent basis. In case of hemicelluloses, if the figure is calculated except a water molecule jointly, it will be of around $100 \%$. For lignin, there existed lignin-derived products $(13.90+6.46)$ and water-insoluble residue (12.24) so that most of the lignin-derived products were identified. On 
1 the other hand, the residue of Japanese cedar after the two-step treatment did not show any

2 presence of cellulose, as inspected by the Klason lignin determination. Thus, the total

3 products from cellulose were relatively low in comparison with hemicelluloses and lignin.

4 However, this missing part of cellulose is not known yet at this moment.

\section{Decomposition pathway of hemicelluloses}

Cellulose hydrolysis as treated by hot-compressed water has been well and adequately studied $^{33,34}$. In our previous work ${ }^{15}$, moreover, its decomposition pathway has been reported. However, there is no hydrolysis pathway of softwood hemicelluloses reported in detail. In this paper, the pathways of both major and minor hemicelluloses in softwood as treated hot-compressed water were proposed independently.

Fig. 7 shows the decomposition pathway of the major hemicellulose in softwood, $O$-acetyl-galactoglucomannan. The dehydration reaction could be confirmed because dehydrated products (5-HMF and levoglucosan) from hexoses (glucose, mannose and galactose) were detected in the first stage, while the formation of the fragmentation product (methylglyoxal) could be attributed to fragmentation reaction of theses hexoses as well. As the other possible fragmented product, erythrose from hexoses, on the other hand, was not detected in the first stage. It could be, therefore, inferred that the 6-carbon carbohydrates might be stable or the decomposition into erythrose might not occur at the low temperature of 
1 the first stage. In addition, although there was a large amount of glucomanno-saccharides

2 produced in the first stage, glucose was formed very less, as described earlier. As a result,

3 fructose was scarcely produced at this stage, as seen in Table 2 . The other reason that might

4 explain this low fructose yield is that the isomerization reaction preferentially proceeds in a

5 higher temperature under the studied conditions. By this reason, thus the isomerization of

6 glucose to fructose was not included in this proposed pathway of the hemicellulose.

7 The decomposition pathway of the minor hemicellulose in softwood, arabino-4-O-methylglucuronoxylan, is shown in Fig. 8. In the same manner, its dehydration and fragmentation reactions were confirmed by the production of furfural, glycolaldehyde and methylglyoxal from the constituent pentoses in this hemicellulose such as xylose and arabinose.

\section{Concluding remarks}

The two-step semi-flow hot-compressed water treatment was applied to the hydrolysis of Japanese cedar. It was found that the two-step treatment was proved to be effective to obtain hydrolyzed products from hemicelluloses and cellulose, separately. As a result, the predominant softwood hemicellulose, $O$-acetyl-galactoglucomannan (glucomannan) was hydrolyzed to be glucomanno-saccharides, such as mannose, glucose and oligomeric glucomannan, galactose and acetic acid, while the minor component of softwood 
1 hemicelluloses, arabino-4-O-methylglucuronoxylan (xylan), to be xylo-saccharides, such as

2 xylose and xylo-oligosaccharides, glucuronic acid and arabinose. The para-crystalline

3 cellulose was found to be readily hydrolyzed at $230^{\circ} \mathrm{C} / 10 \mathrm{MPa}$ into cello-saccharides, such as

4 glucose and cello-oligosaccharides, in the first stage, starting from the retention time of 10

5 min. This result was evidently attributed to the same finding in our previous study on

6 Japanese beech ${ }^{15}$ that there existed also the hydrolysis of para-crystalline cellulose at the same

7 conditions in the first stage, while crystalline cellulose was hydrolyzed at $280^{\circ} \mathrm{C} / 10 \mathrm{MPa}$. In

8 addition, glucose, hydrolyzed product of cellulose, was found to be isomerized to fructose and

9 mannose during the second stage. Upon lignin, it was decomposed at even lower temperature

10 to produce coniferyl alcohol and its aldehyde and fragmented compounds. These lines of

11 information are very important and useful to utilize efficiently various kinds of lignocellulosic

12 materials for biochemicals and biofuels. 


\section{Acknowledgements}

This work has been done as in part of the NEDO project (FYs 2007-2010) "Eco-ethanol

3 production from lignocellulosics with hot-compressed water treatment followed by acetic acid

4 fermentation and hydrogenolysis", and under the partially financial support by the Global

5 Center of Excellence (GCOE) Program, Kyoto University, for all of which the authors are

6 highly acknowledged. 


\section{Figure legends}

Fig. 1 Hydrolyzed products from Japanese cedar as treated by two-step semi-flow hot-compressed water at $230^{\circ} \mathrm{C} / 10 \mathrm{MPa} / 15 \mathrm{~min}$ and $280^{\circ} \mathrm{C} / 10 \mathrm{MPa} / 30 \mathrm{~min}$. Left axis corresponds to treatment temperature (open circles); right axis corresponds to product yield.

Fig. 2 Monosaccharides from Japanese cedar as treated by two-step semi-flow hot-compressed water at $230^{\circ} \mathrm{C} / 10 \mathrm{MPa} / 15 \mathrm{~min}$ and $280^{\circ} \mathrm{C} / 10 \mathrm{MPa} / 30 \mathrm{~min}$. An arrow shows the presence of mannose in the first stage, while an inserted figure is the enlarged one of the fructose and mannose peaks in the second stage.

Fig. 3 Lignin-derived monomeric products from Japanese cedar as treated by two-step semi-flow hot-compressed water at $230^{\circ} \mathrm{C} / 10 \mathrm{MPa} / 15 \mathrm{~min}$ and $280^{\circ} \mathrm{C} / 10 \mathrm{MPa} / 30 \mathrm{~min}$

Fig. 4 Dehydrated compounds produced from Japanese cedar as treated by two-step semi-flow hot-compressed water at $230^{\circ} \mathrm{C} / 10 \mathrm{MPa} / 15 \mathrm{~min}$ and $280^{\circ} \mathrm{C} / 10 \mathrm{MPa} / 30 \mathrm{~min}$

Fig. 5 Fragmented compounds produced from Japanese cedar as treated by two-step semi-flow hot-compressed water at $230^{\circ} \mathrm{C} / 10 \mathrm{MPa} / 15 \mathrm{~min}$ and $280^{\circ} \mathrm{C} / 10 \mathrm{MPa} / 30 \mathrm{~min}$

Fig. 6 Organic acids produced from Japanese cedar as treated by two-step semi-flow hot-compressed water at $230^{\circ} \mathrm{C} / 10 \mathrm{MPa} / 15 \mathrm{~min}$ and $280^{\circ} \mathrm{C} / 10 \mathrm{MPa} / 30 \mathrm{~min}$

Fig. 7 The proposed decomposition pathway of $O$-acetyl-galactoglucomannan in Japanese cedar as treated by two-step semi-flow hot-compressed water at 
$230^{\circ} \mathrm{C} / 10 \mathrm{MPa} / 15 \mathrm{~min}$ and $280^{\circ} \mathrm{C} / 10 \mathrm{MPa} / 30 \mathrm{~min}$

Fig. 8 The proposed decomposition pathway of arabino-4- $O$-methylglucuronoxylan in Japanese cedar as treated by two-step semi-flow hot-compressed water at $230^{\circ} \mathrm{C} / 10 \mathrm{MPa} / 15 \mathrm{~min}$ and $280^{\circ} \mathrm{C} / 10 \mathrm{MPa} / 30 \mathrm{~min}$ 


\section{References}

1. Solomon BD, Barnes JR, Halvorsen KE (2007) Grain and cellulosic ethanol: History, economics, and energy policy. Biomass Bioenerg 31: 416-425

2. Galbe M, Zacchi G (2002) A review of the production of ethanol from softwood. Appl Microbiol Biotechnol 59: 618-628

3. Walch E, Zemann A, Schinner F, Bonn G, Bobleter O (1992) Enzymatic saccharification of hemicellulose obtained from hydrothermally pretreated sugar cane bagasse and beech bark. Biores Technol 39: 173-177

4. Torget R, Werdene P, Himmel M, Grohmann K (1990) Dilute acid pretreatment of short rotation woody and herbaceous crops. Appl Biochem Biotechnol 24-25: 115-126

5. Targoński Z (1985) Alkali process for enhancing susceptibility of autohydrolysed beech sawdust to enzymeatic hydrolysis. Enzyme Microb Technol 7: 126-128

6. Heitz M, Capek-Ménard E, Koeberle PG, Gagné J, Chornet E, Overend RP, Taylor JD, Yu E (1991) Fractionation of Populus tremuloides at pilot plant scale: Optimization of steam pretreatment conditions using the STAKE II technology. Biores Technol 35: 23-32

7. Saka S, Konishi R (2001) Chemical conversion of biomass resources to useful chemicals and fuels by supercritical water treatment. In: Bridgwater AV (ed) Progress in thermochemical biomass conversion, Blackwell, Oxford, pp 1338-1348

8. Aida TM, Sato Y, Watanabe M, Tajima K, Nonaka T, Hattori H, Arai K (2007) 
Dehydration of D-glucose in high temperature water at pressures up to 80MPa. J Supercrit Fluid 40: 381-388

9. Sasaki M, Kabyemela B, Malaluan R, Hirose S, Takeda N, Adschiri T, Arai K (1998) Cellulose hydrolysis in subcritical and supercritical water. J Supercrit Fluid 13: 261-268

10. Ando H, Sakaki T, Kokusho T, Shibata M, Uemura Y, Hatate Y (2000) Decomposition behavior of plant biomass in hot-compressed water. Ind Eng Chem Res 39: 3688-3693

11. Rogalinski T, Ingram T, Brunner G (2008) Hydrolysis of lignocellulosics biomass in water under elevated temperatures and pressures. J Supercrit Fluid 47: 54-63

12. Ehara K, Takada D, Saka S (2005) GC-MS and IR spectroscopic analyses of the lignin-derived products from softwood and hardwood treated in supercritical water. $\mathbf{J}$ Wood Sci 51: 256-261

13. Söderström J, Pilcher L, Galbe M, Zacchi G (2002) Two-step steam pretreatment of softwood with $\mathrm{SO}_{2}$ impregnation for ethanol production. Appl Biochem Biotech 98-100:

\section{$5-21$}

14. Bobleter O (1994) Hydrothermal degradation of polymers derived from plants. Prog Polym Sci 19: 797-841

15. Lu X, Yamauchi K, Phaiboonsilpa N, Saka S (2009) Two-step hydrolysis of Japanese beech as treated by semi-flow hot-compressed water. J Wood Sci 55: 367-375

16. Phaiboonsilpa N, Lu X, Yamauchi K, Saka S (2009) Chemical conversion of 
lignocellulosics as treated by two-step semi-flow hot-compressed water. In: Proceedings of the World Renewable Energy Congress 2009 - Asia, 19-21 May, 2009, Bangkok, Thailand, pp 235-240

17. Dence CW (1992) The determination of lignin. In: Lin SY, Dence CW (eds) Methods in Lignin Chemistry, Springer, Berlin, Germany, pp 33-63

18. Yang B, Wyman CE (2008) Characterization of the degree of polymerization of xylooligomers produced by flowthrough hydrolysis of pure xylan and corn stover with water. Bioresource Technol 99: 5756-5762

19. Timell TE (1967) Recent progress in chemistry of wood hemicelluloses. Wood Sci Technol 1: 45-70

20. Lundqvist J, Teleman A, Junel L, Zacchi G, Dahlman O, Tjerneld F, Stålbran H (2002) Isolation and characterization of galactoglucomannan from spruce (Picea abies). Carbohyd Polym 48: 29-39

21. Kabyemela BM, Adschiri T, Malaluan R, Arai K (1999) Glucose and fructose decomposition in subcritical and supercritical water: detailed reaction pathway, mechanisms, and kinetics. Ind Eng Chem Res 38: 2888-2895

22. Srokol Z, Bouche AG, van Estrik A, Strik RCJ, Maschmeyer T, Peters JA (2004) Hydrothernal upgrading of biomass to biofuel: studies on some monosaccharides model compounds. Carbohydr Res 339: 1717-1726 
23. Larsson PT, Wickolm K, Iversen T (1997) A CP/MAS 13C NMR investigation of molecular ordering in celluloses. Carbohyd Res 302: 19-25

24. Kruse A, Dinjus E (2007) Hot compressed water as reaction medium and reactant 2. Degradation reactions. J Supercrit Fluids 41: 361-379

25. Palmqvist E, Hahn-Hägerdal B (2000) Fermentation of lignocellulosic hydrolysates. II: inhibitors and mechanisms of inhibition. Bioresource Technol 74: 25-33

26. Antal MJ, Leesomboon T, Mok WS, Richards GN (1991) Mechanism of formation of 2-furaldehyde from D-xylose. Carhohyd Res 217: 71-85

27. Kallury RKMR, Ambidge C, Tidwell TT, Boocock DGB, Agblevor FA, Stewart DJ (1986) Rapid hydrothermolysis of cellulose and related carbohydrates. Carbohydr Res 158: $253-261$

28. Kabyemela BM, Adschiri T, Malaluan R, Arai K (1997) Degradation kinetics of dihydroxyacetone and glyceraldehyde in subcritical and supercritical water. Ind Eng Chem Res 36: 2025-2030

29. Watanabe M, Aizawa Y, Iida T, Levy C, Aida TM, Inomata H (2005) Glucose reactions within the heating period and the effect of heating rate on the reactions in hot compressed water. Carbohydr Res 340: 1931-1939

30. Kabyemela BM, Adschiri T, Malaluan RM, Arai K, Ohzeki H (1997) Rapid and Selective Conversion of Glucose to Erythrose in Supercritical Water. Ind Eng Chem Res 36: 
5063-5067

31. Yoshida K, Kusaki J, Ehara K, Saka S (2005) Characterization of low molecular weight organic acids from beech wood treated in supercritical water. Appl Biochem Biotechnol 121-124: 795-806

32. Matsunaga M, Matsui H, Otsuka Y, Yamamoto S (2008) Chemical conversion of wood by treatment in semi-batch reactor with subcritical water. J Supercrit Fluid 44: 364-369

33. Ehara K, Saka S (2002) A comparative study on chemical conversion of cellulose between the batch-type and flow-type systems in supercritical water. Cellulose 9: 301-311

34. Sasaki M, Furukawa M, Minami K, Adschiri T, Arai K (2002) Kinetics and Mechanism of Cellobiose Hydrolysis and Retro-Aldol Condensation in Subcritical and Supercritical Water. Ind Eng Chem Res 41: 6642-6649 
Table 1 Cell wall components of extractive-free Japanese cedar used in this study ${ }^{16}$ wt\% on extractive-free wood flour basis

\begin{tabular}{|c|c|c|c|c|}
\hline \multicolumn{2}{|c|}{ Hemicelluloses } & \multirow{2}{*}{ Cellulose } & \multicolumn{2}{|c|}{ Lignin } \\
\hline Glucomannan & Xylan & & Klason lignin & Acid-soluble lignin \\
\hline 12.41 & 6.69 & 48.32 & 32.20 & 0.38 \\
\hline
\end{tabular}


Table 2 Summary of various products produced from Japanese cedar as treated by two-step semi-flow hot-compressed water at $230^{\circ} \mathrm{C} / 10 \mathrm{MPa} / 15 \mathrm{~min}$ and $280^{\circ} \mathrm{C} / 10 \mathrm{MPa} / 30 \mathrm{~min}$

\begin{tabular}{|c|c|c|c|c|c|c|c|}
\hline \multirow{3}{*}{ Compound } & \multicolumn{7}{|c|}{ Yield (wt\%) } \\
\hline & \multicolumn{3}{|c|}{ First stage $^{\dagger}$} & \multicolumn{3}{|c|}{ Second stage $^{\dagger}$} & \multirow{2}{*}{ Total } \\
\hline & Hemicell & Cellulose & Lignin & Hemicell & Cellulose & Lignin & \\
\hline \multicolumn{8}{|c|}{ Hydrolyzed products from hemicelluloses and cellulose } \\
\hline & 19.24 & 2.95 & - & 0.25 & 17.77 & - & 40.21 \\
\hline $\begin{array}{l}\text { - Glucomanno- } \\
\text { saccharides }\end{array}$ & 11.54 & - & - & $0.17^{*}$ & - & - & 11.71 \\
\hline - Galactose & 1.33 & - & - & - & - & - & 1.33 \\
\hline - Acetic acid & 0.09 & - & - & - & $0.07^{* *}$ & - & 0.16 \\
\hline - Xylo-saccharides & 5.37 & - & - & $0.08^{*}$ & - & - & 5.45 \\
\hline - Arabinose & 0.85 & - & - & - & - & - & 0.85 \\
\hline - Glucuronic acid & 0.06 & - & - & - & - & - & 0.06 \\
\hline - Cello-saccharides & - & $2.94^{+}$ & - & - & 17.05 & - & 19.99 \\
\hline - Fructose & - & $0.01^{*}$ & - & - & $0.65^{*}$ & - & 0.66 \\
\hline \multicolumn{8}{|l|}{ Dehydrated compounds } \\
\hline & 0.22 & - & - & - & 3.84 & - & 4.06 \\
\hline - 5-HMF & 0.10 & - & - & - & 3.12 & - & 3.22 \\
\hline - Furfural & 0.03 & - & - & - & 0.22 & - & 0.25 \\
\hline - Levoglucosan & 0.09 & - & - & - & 0.50 & - & 0.59 \\
\hline \multicolumn{8}{|l|}{ Fragmented compounds } \\
\hline & 1.63 & - & - & - & 2.25 & - & 3.88 \\
\hline - Erythrose & - & - & - & - & 0.45 & - & 0.45 \\
\hline - Methylglyoxal & 1.07 & - & - & - & 1.19 & - & 2.26 \\
\hline - Glycolaldehyde & 0.56 & - & - & - & 0.61 & - & 1.17 \\
\hline \multicolumn{8}{|l|}{ Organic acids } \\
\hline & 0.23 & - & - & - & 0.45 & - & 0.68 \\
\hline - Lactic acid & 0.05 & - & - & - & 0.14 & - & 0.19 \\
\hline - Glycolic acid & 0.06 & - & - & - & 0.15 & - & 0.21 \\
\hline - Formic acid & 0.12 & - & - & - & 0.16 & - & 0.28 \\
\hline \multicolumn{8}{|l|}{$\underline{\text { Lignin-derived products }}$} \\
\hline & - & - & 13.90 & - & - & 6.46 & 20.36 \\
\hline - Vanillin & - & - & 0.06 & - & - & 0.05 & 0.11 \\
\hline - Isoeugenol & - & - & 0.02 & - & - & 0.02 & 0.04 \\
\hline - Coniferaldehyde & - & - & 0.15 & - & - & 0.05 & 0.20 \\
\hline - Coniferyl alcohol & - & - & 0.81 & - & - & 0.11 & 0.92 \\
\hline $\begin{array}{l}\text { - Dimeric, trimeric and } \\
\text { higher products }\end{array}$ & - & - & 12.86 & - & - & 6.23 & 19.09 \\
\hline
\end{tabular}




\begin{tabular}{llllllll}
\hline Total & 21.32 & 2.95 & 13.90 & 0.25 & 24.31 & 6.46 & 69.19 \\
\hline Unknowns & - & - & - & - & - & - & 18.57 \\
\hline Water-insoluble residue & & & & & & 12.24 \\
\hline
\end{tabular}

Remarks:

The term "Hemicell" refers to hemicelluloses.

$\dagger$ including the transient time

+ Cello-saccharides produced from hydrolysis of para-crystalline cellulose

$\$$ Fructose, as an isomerized product of glucose, is considered as the hydrolyzed product from cellulose.

* Glucomanno-saccharides and xylo-saccharides from the hemicelluloses incompletely hydrolyzed in the first stage; In case of glucomanno-saccharides, mannose derived from an isomerization of glucose is included as well. ** Acetic acid produced from decomposition of cellulose 


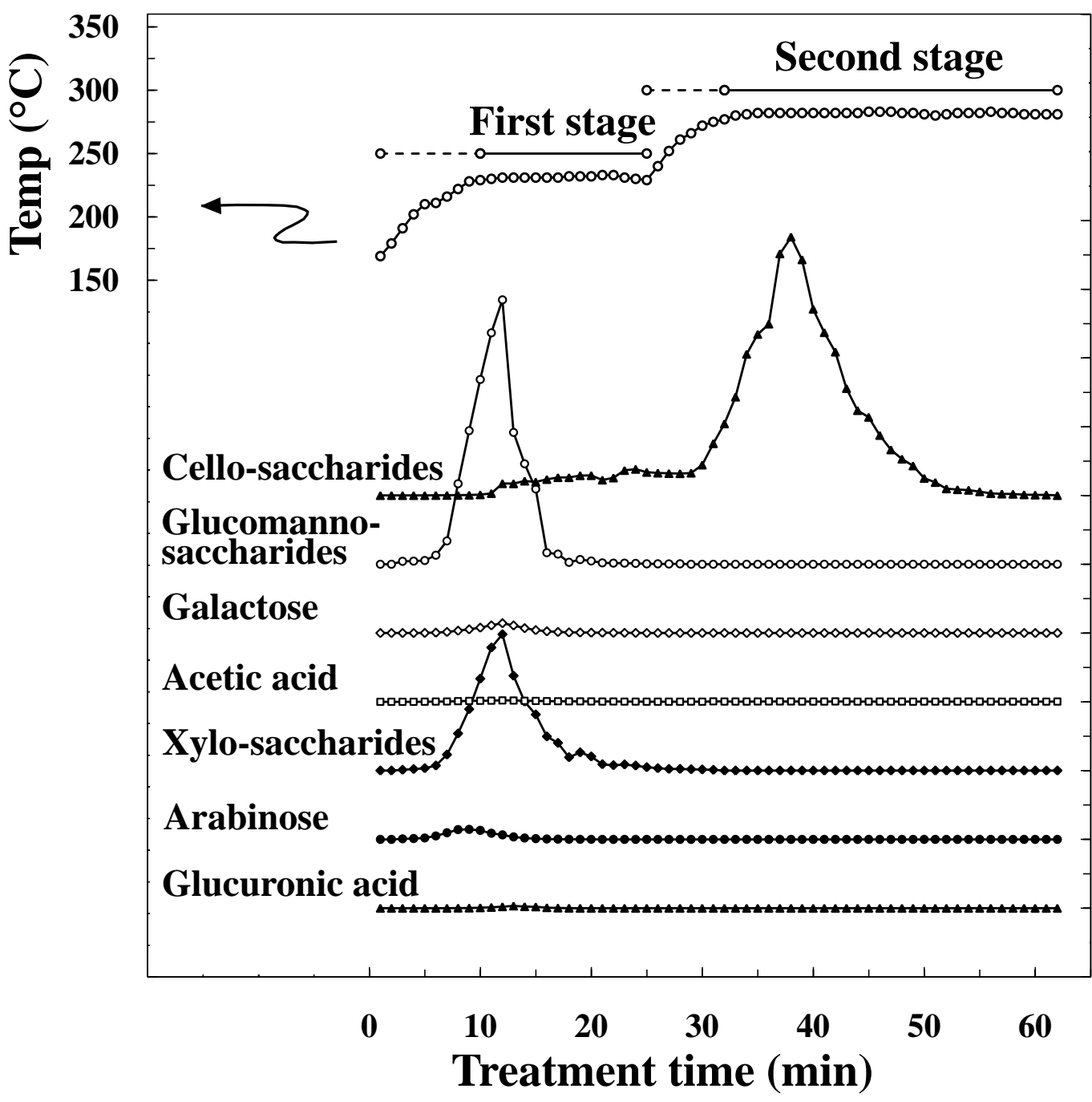

Fig. 1 Hydrolyzed products from Japanese cedar as treated by two-step semi-flow hot-compressed water at $230^{\circ} \mathrm{C} / 10 \mathrm{MPa} / 15 \mathrm{~min}$ and $280^{\circ} \mathrm{C} / 10 \mathrm{MPa} / 30 \mathrm{~min}$. Left axis corresponds to treatment temperature (open circles); right axis corresponds to product yield. 


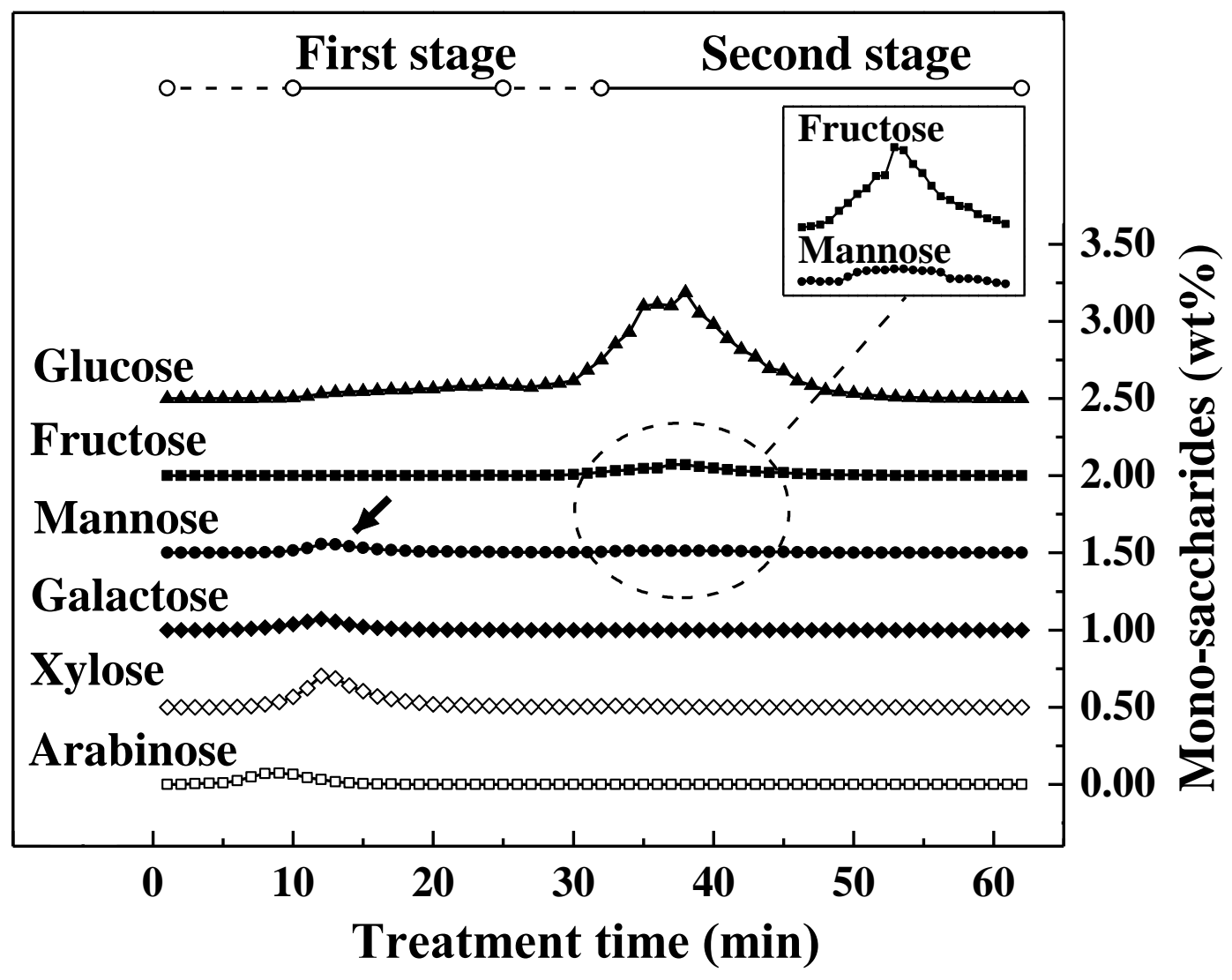

Fig. 2 Monosaccharides from Japanese cedar as treated by two-step semi-flow hot-compressed water at $230^{\circ} \mathrm{C} / 10 \mathrm{MPa} / 15 \mathrm{~min}$ and $280^{\circ} \mathrm{C} / 10 \mathrm{MPa} / 30 \mathrm{~min}$. An arrow shows the presence of mannose in the first stage, while an inserted figure is the enlarged one of the fructose and mannose peaks in the second stage. 


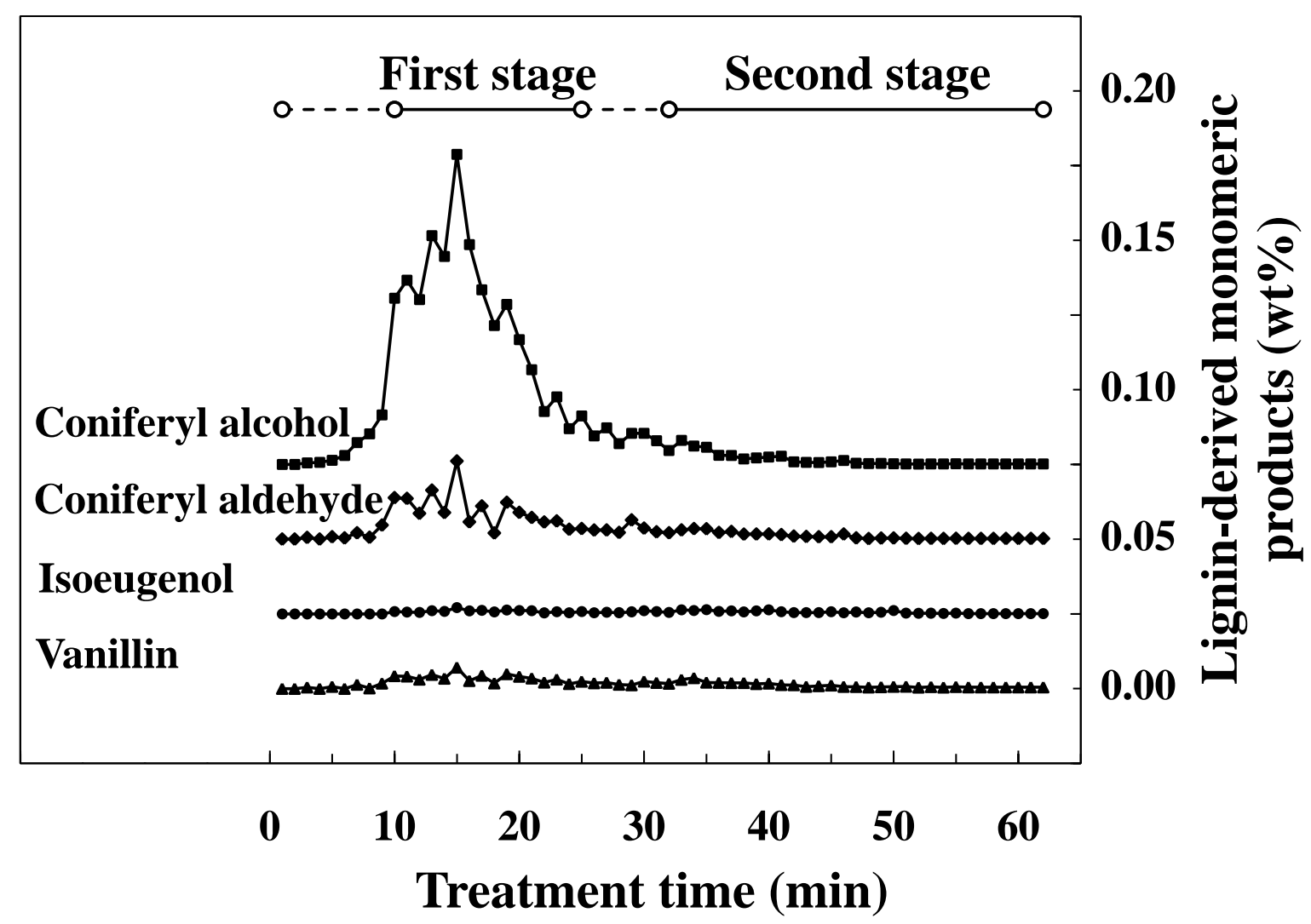

Fig. 3 Lignin-derived monomeric products from Japanese cedar as treated by two-step semi-flow hot-compressed water at $230^{\circ} \mathrm{C} / 10 \mathrm{MPa} / 15 \mathrm{~min}$ and $280^{\circ} \mathrm{C} / 10 \mathrm{MPa} / 30 \mathrm{~min}$ 


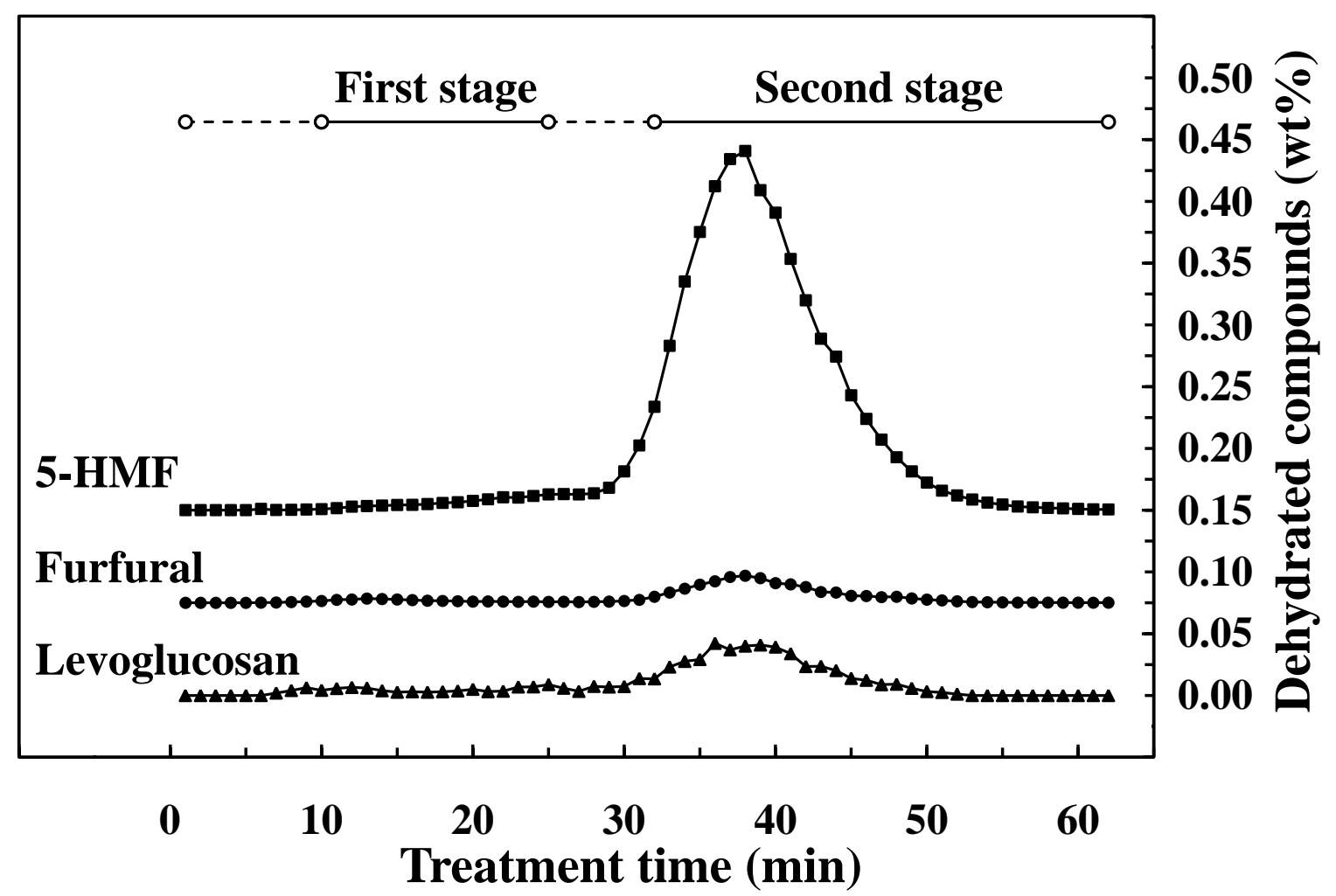

Fig. 4 Dehydrated compounds produced from Japanese cedar as treated by two-step semi-flow hot-compressed water at $230^{\circ} \mathrm{C} / 10 \mathrm{MPa} / 15 \mathrm{~min}$ and $280^{\circ} \mathrm{C} / 10 \mathrm{MPa} / 30 \mathrm{~min}$ 


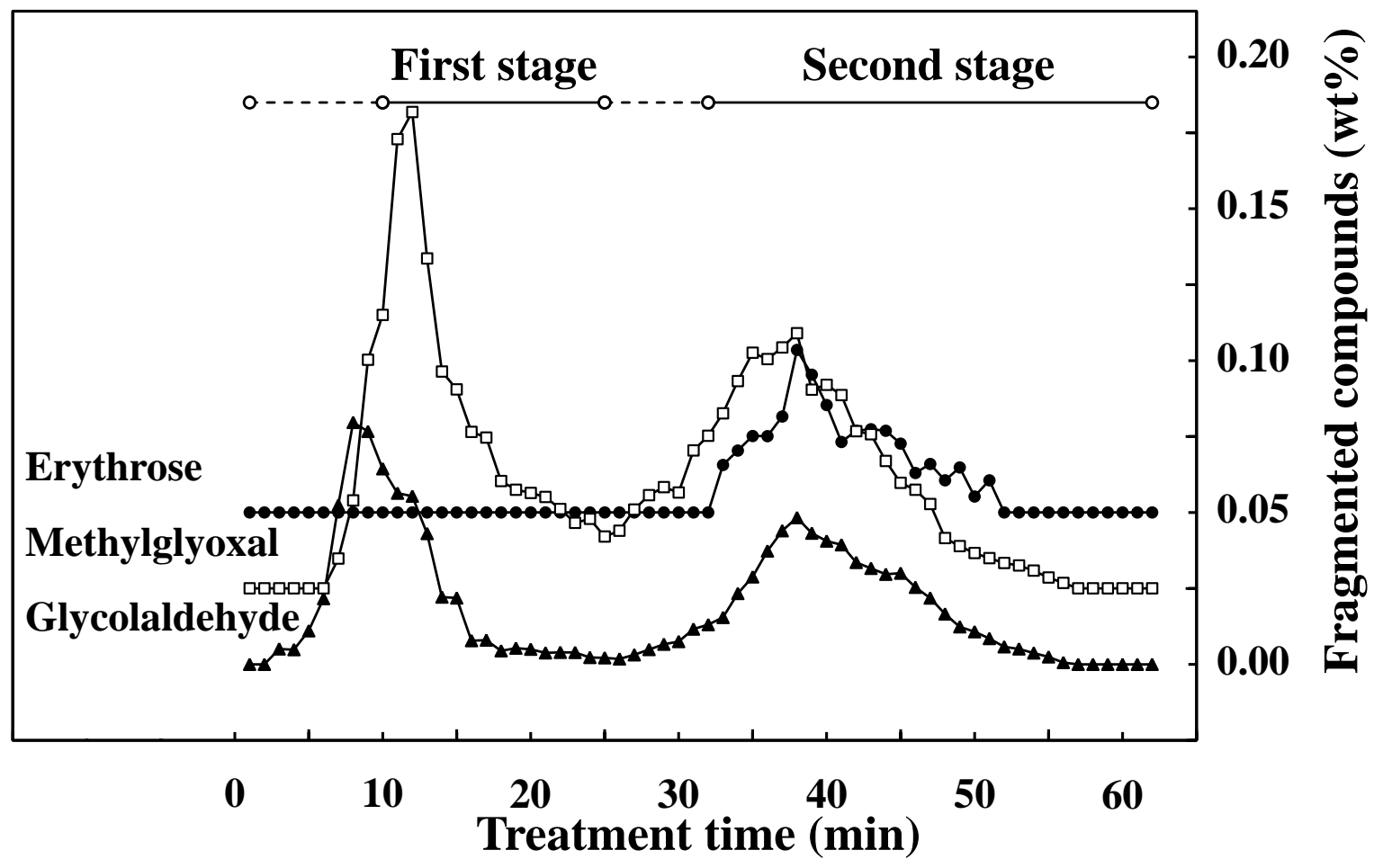

Fig. 5 Fragmented compounds produced from Japanese cedar as treated by two-step semi-flow hot-compressed water at $230^{\circ} \mathrm{C} / 10 \mathrm{MPa} / 15 \mathrm{~min}$ and $280^{\circ} \mathrm{C} / 10 \mathrm{MPa} / 30 \mathrm{~min}$ 


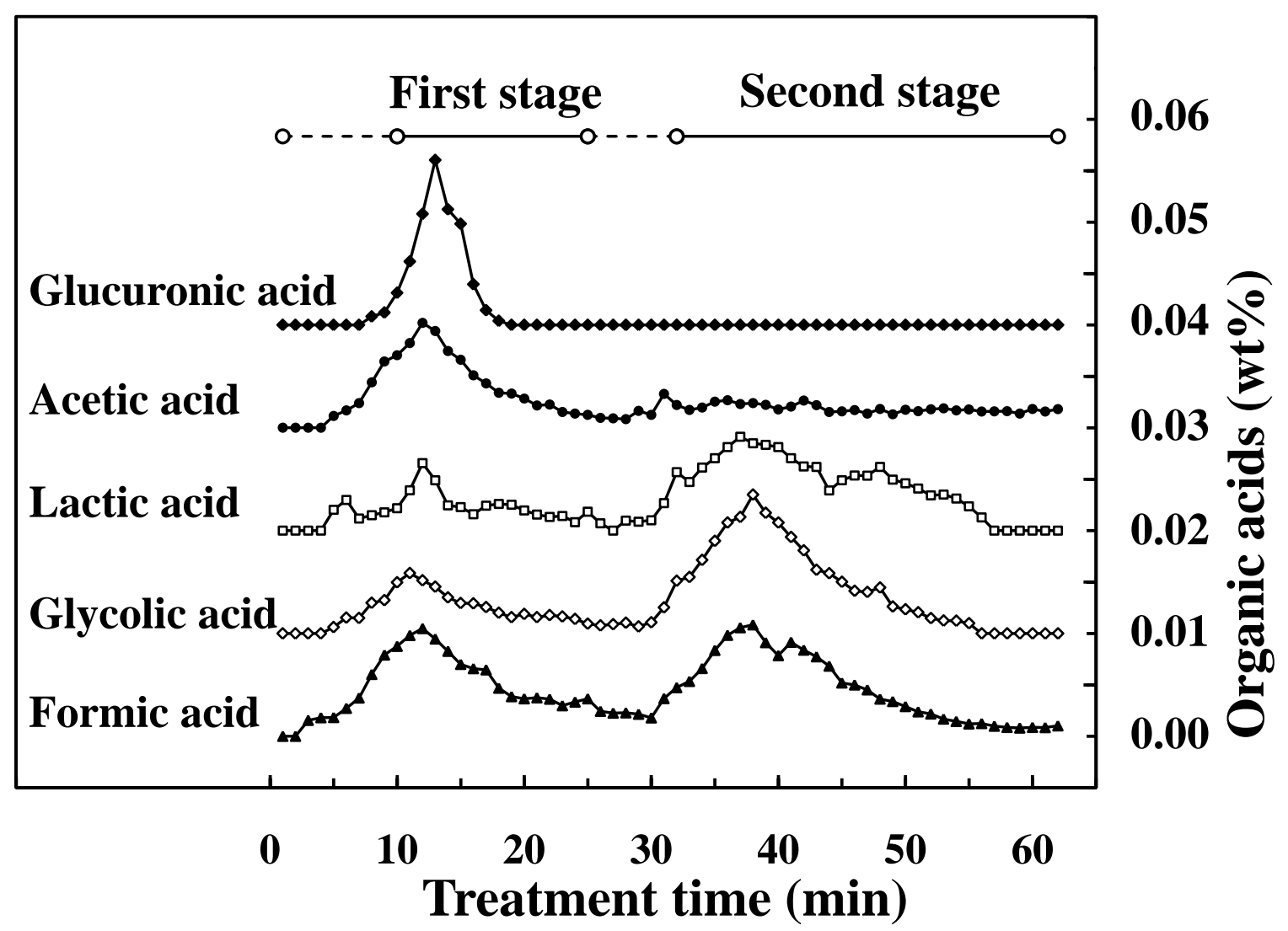

Fig. 6 Organic acids produced from Japanese cedar as treated by two-step semi-flow hot-compressed water at $230^{\circ} \mathrm{C} / 10 \mathrm{MPa} / 15 \mathrm{~min}$ and $280^{\circ} \mathrm{C} / 10 \mathrm{MPa} / 30 \mathrm{~min}$ 


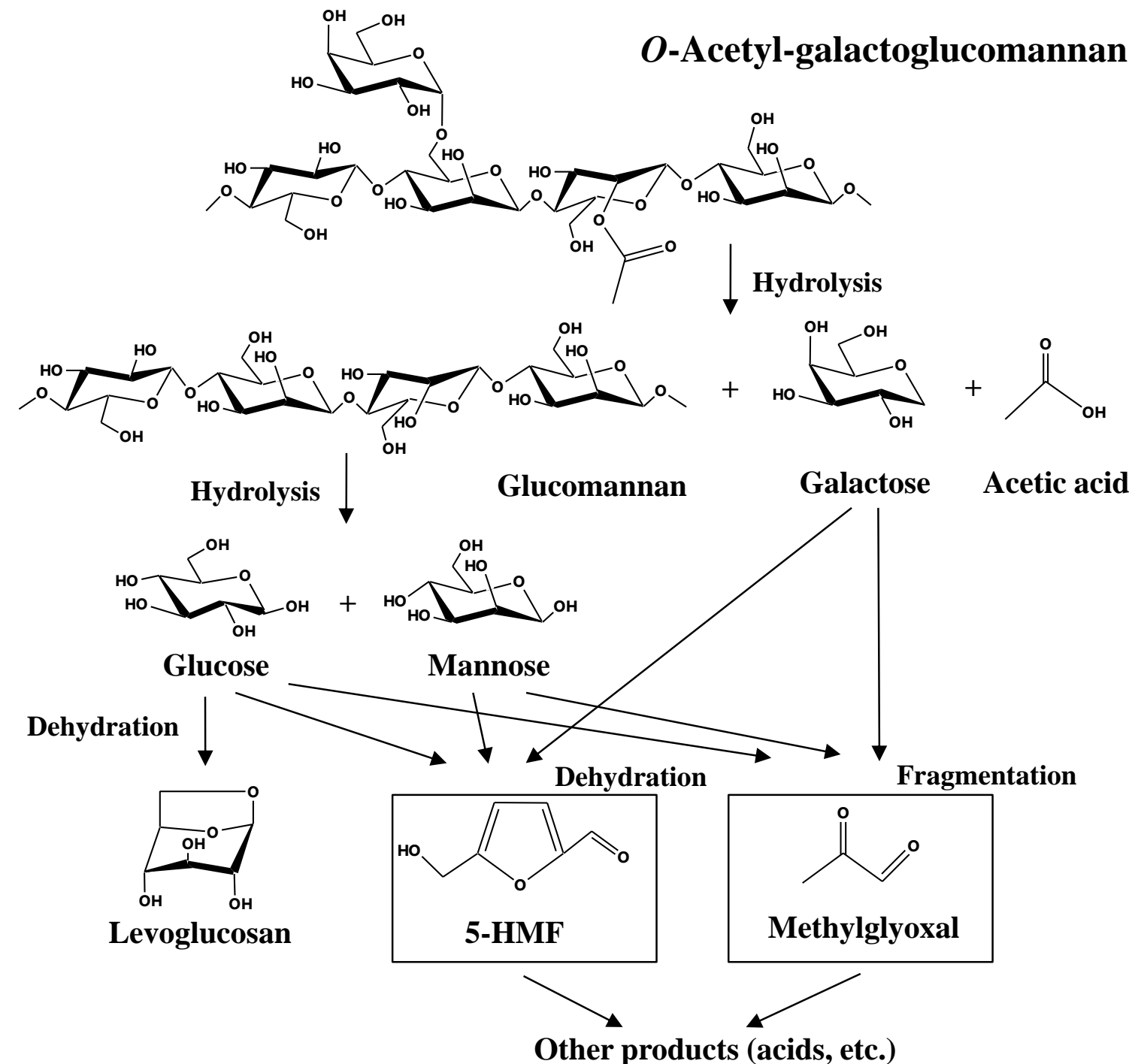

Fig. 7 The proposed decomposition pathway of $O$-acetyl-galactoglucomannan in Japanese cedar as treated by two-step semi-flow hot-compressed water at $230^{\circ} \mathrm{C} / 10 \mathrm{MPa} / 15 \mathrm{~min}$ and $280^{\circ} \mathrm{C} / 10 \mathrm{MPa} / 30 \mathrm{~min}$ 

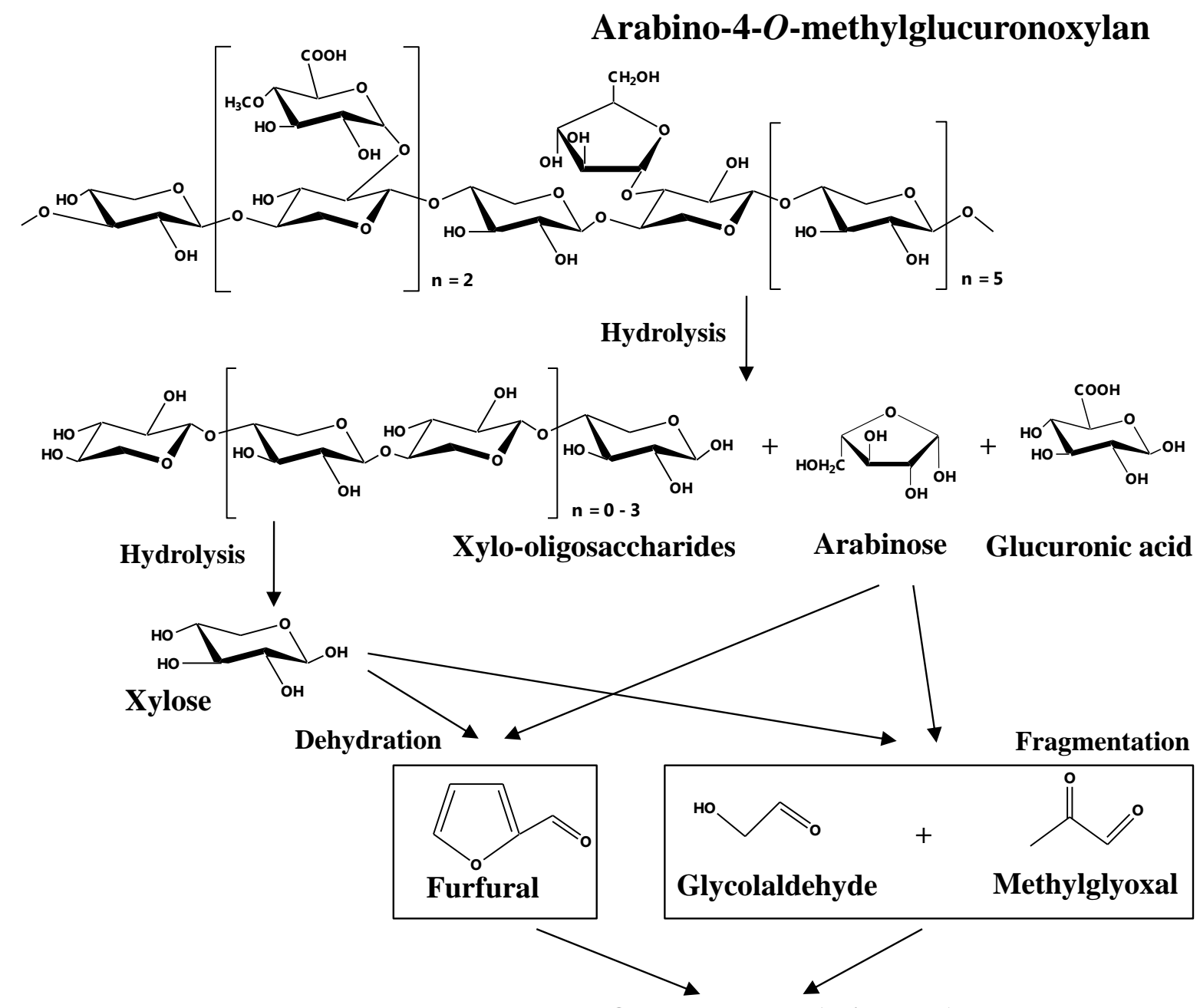

Other products (acids, etc.)

Fig. 8 The proposed decomposition pathway of arabino-4-O-methylglucuronoxylan in Japanese cedar as treated by two-step semi-flow hot-compressed water at $230^{\circ} \mathrm{C} / 10 \mathrm{MPa} / 15 \mathrm{~min}$ and $280^{\circ} \mathrm{C} / 10 \mathrm{MPa} / 30 \mathrm{~min}$ 